\title{
Etching Properties of ZnS:Mn Thin Films in an Inductively Coupled Plasma
}

\author{
Gwan-Ha Kim, Jong-Chang Woo, Kyoung-Tae Kim, Dong-Pyo Kim, and Chang-Il Kim ${ }^{\mathrm{a}}$ \\ School of Electrical and Electronics Engineering, Chung-ang University, \\ 221 Huksuk-dong, Dongjak-gu, Seoul 156-756, Korea \\ ${ }^{\mathrm{a}}$ E-mail : $\underline{\text { cikim } @ \text { cau.ac.kr }}$
}

(Received October 15 2007, Accepted February 16 2008)

\begin{abstract}
$\mathrm{ZnS}$ is an attractive material for future optical and electrical devices since it has a direct and wide band gap to provide blue emission at room temperature. In this study, inductively coupled $\mathrm{BCl}_{3} / \mathrm{Ar}$ plasma was used to etch $\mathrm{ZnS}: \mathrm{Mn}$ thin films. The maximum etch rate of $164.2 \mathrm{~nm} / \mathrm{min}$ for $\mathrm{ZnS}: \mathrm{Mn}$ was obtained at a $\mathrm{BCl}_{3}(20) / \mathrm{Ar}(80)$ gas mixing ratio, an rf power of $700 \mathrm{~W}$, a dc bias voltage of $-200 \mathrm{~V}$, a total gas flow of $20 \mathrm{sccm}$, and a chamber pressure of 1 $\mathrm{Pa}$. The etch behaviors of $\mathrm{ZnS}: \mathrm{Mn}$ thin films under various plasma parameters showed that the $\mathrm{ZnS}: \mathrm{Mn}$ were effectively removed by the chemically assisted physical etching mechanism. The surface reaction of the ZnS:Mn thin films was investigated by X-ray photoelectron spectroscopy. The XPS analysis revealed that Mn had detected on the surface $\mathrm{ZnS}: \mathrm{Mn}$ etched in $\mathrm{BCl}_{3} / \mathrm{Ar}$ plasma.
\end{abstract}

Keywords : Zinc sulfide, Etching, Electroluminescence device, Inductively coupled plasma

\section{INTRODUCTION}

Zinc sulfide $(\mathrm{ZnS})$ is a wide band gap material to provide blue rays at room temperature. The $\mathrm{ZnS}$ thin film has successfully utilized in optoelectric device applications, such as optical coatings, gate dielectrics, filters, and reflectors[1]. Especially, Mn- or Tb-doped $\mathrm{ZnS}$ thin films have been widely employed as electroluminescent (EL) phosphor for the application of thin film electroluminescent (TFEL) devices because they offer high brightness and wide viewing angle. The TFEL is composed of bottom electrode, lower insulator, phosphor, upper insulator, and top electrode. The total thickness of TFEL device is as thin as a few micrometers. The simplicity of structure and the thickness of TFEL provide a great potential to be a very high-resolution flat panel display. Especially, in order to overcome crosstalk problem for the color TFEL display devices, it is essential to selectively etch the phosphor layer against the under-layer such as lower insulating layer or etch barrier layer. Therefore, it is very important to develop the micro-patterning process using plasma etch technology.

$\mathrm{CH}_{4} / \mathrm{H}_{2}$ chemistries had been used to etch $\mathrm{ZnS}$ with high dc-self biases and resulted in low etch rate of under $30 \mathrm{~nm}[1-5]$. It reported that the use of $\mathrm{CH}_{4} / \mathrm{H}_{2}$ gas mixture results in the formation of hydrocarbon polymer, plasma induced damage and a poor reproducibility of the etch process. Inductively coupled plasma (ICP) has some advantages such as high ion density and high etch rate compared to the reactive ion etching (RIE) and could overcome the problems of photo-resist burning or swelling in ECR plasma.

In this work, $\mathrm{ZnS}: \mathrm{Mn}$ thin films were etched in $\mathrm{BCl}_{3} / \mathrm{Ar}$ plasma with using ICP etch system. The etch characteristics of $\mathrm{ZnS}: \mathrm{Mn}$ thin films systematically investigated with various gas mixing ratio, source RF power, $\mathrm{dc}$ bias voltage, and working pressure. The surface states of etched $\mathrm{ZnS}: \mathrm{Mn}$ thin film was examined with using X-ray photoelectron spectroscopy (XPS).

\section{EXPERIMENTAL}

The Mn-doped ZnS:Mn (0.39 wt.\%) thin films were prepared with using RF magnetron sputtering method. The etching experiments of $\mathrm{ZnS}: \mathrm{Mn}$ were performed in ICP etch system[6]. The standard conditions were a working pressure of $1 \mathrm{~Pa}$, an RF power of $700 \mathrm{~W}$ and $\mathrm{DC}$ bias voltage of $-200 \mathrm{~V}$. The total flow rate of 20 sccm for $\mathrm{BCl}_{3} / \mathrm{Ar}$ gas mixing ratio was fed through a mass flow controller. We discussed the effect of $\mathrm{BCl}_{3} / \mathrm{Ar}$ gas mixing ratio in the etch of $\mathrm{ZnS}: \mathrm{Mn}$. The behaviors of etch rates were also discussed with RF source power, DC bias voltage and working pressure. The etch rates were obtained from surface-profiler (alpha-Step 500, KLA Tencor) after etching $\mathrm{ZnS}: \mathrm{Mn}$ for $1 \mathrm{~min}$ and removal of the patterned photoresist (AZ1512). The chemical 
reactions between $\mathrm{BCl}_{3} / \mathrm{Ar}$ plasma and $\mathrm{ZnS}: \mathrm{Mn}$ thin film was investigated with using an XPS (ESCALAB 200R. VG Scientific) with $\mathrm{Mg} \mathrm{K}_{\alpha}(1253.6 \mathrm{eV})$ radiation at 300 $\mathrm{W}$. The surface composition and the chemical binding states of the constituents were analyzed with an XPS narrow scan spectra with $20 \mathrm{eV}$ passing energy.

\section{RESULTS AND DISCUSSION}

The etch result is affected by both chemical and physical mechanisms when the binary mixture of the chemically-active gas with a noble gas is used for the etching process;

(1) The chemical "channel" is controlled by the fluxes of neutral chemically active species on the etched surface.

(2) The physical factor is represented by sputter etching as well as by the activation of chemical reaction through the ion-stimulated desorption of the reaction products.

In such a system, the gas mixing ratio gives a powerful factor to adjust the process results as well as determines the regions where the result is sensitive to the different input parameters. Therefore, the investigation of the etching mechanism requires the simultaneous analysis of the influence of input process parameters on the etch rate behavior and surface kinetics.

Figure 1 shows the etch rates of $\mathrm{ZnS}: \mathrm{Mn}$ thin film and $\mathrm{SiO}_{2}$ as a function of $\mathrm{BCl}_{3} / \mathrm{Ar}$ plasma gas mixing ratio when total flow rate was maintained at $20 \mathrm{sccm}$. The RF power to the source, the DC bias voltage, the working pressure, and the substrate temperature were also maintained at $700 \mathrm{~W},-200 \mathrm{~V}, 1 \mathrm{~Pa}$, and $23{ }^{\circ} \mathrm{C}$, respectively. As the $\mathrm{BCl}_{3}$ addition in $\mathrm{BCl}_{3} /\left(\mathrm{BCl}_{3}+\mathrm{Ar}\right)$ plasma increases from $0 \%$ to $20 \%$, the etch rates of $\mathrm{ZnS}: \mathrm{Mn}$ thin film increases from $134.7 \mathrm{~nm} / \mathrm{min}$ to 164.2 $\mathrm{nm} / \mathrm{min}$. The etch rate of the $\mathrm{ZnS}: \mathrm{Mn}$ reached the maximum value at $20 \% \mathrm{BCl}_{3} / \mathrm{Ar}$ gas concentration and decreased from $161.1 \mathrm{~nm}$ to $114.1 \mathrm{~nm}$ with further addition of $\mathrm{BCl}_{3}$ addition (from $50 \%$ to $100 \%$ ) in $\mathrm{BCl}_{3} /\left(\mathrm{BCl}_{3}+\mathrm{Ar}\right)$ plasma. The etch rate of $\mathrm{SiO}_{2}$ increased from $21.6 \mathrm{~nm} / \mathrm{min}$ to $156.2 \mathrm{~nm} / \mathrm{min}$ as the $\mathrm{BCl}_{3}$ addition in $\mathrm{BCl}_{3} /\left(\mathrm{BCl}_{3}+\mathrm{Ar}\right)$ plasma increases from $0 \%$ to $50 \%$. With further addition over $50 \%$ of the $\mathrm{BCl}_{3}$ addition in $\mathrm{BCl}_{3} / \mathrm{Ar}$, the etch rate of $\mathrm{SiO}_{2}$ shows a little decrease tendency, but maintains some constant.

Comparison of the $\mathrm{ZnS}: \mathrm{Mn}$ etch rates in pure $\mathrm{Ar}$ and pure $\mathrm{BCl}_{3}$ plasmas shows that the chemical etching is less effective than physical sputtering. Non-monotonic behavior of the etch rate in our experiments may be explained as follows; It is well known that some of the components for $\mathrm{ZnS}: \mathrm{Mn}$ form low-volatile chlorides

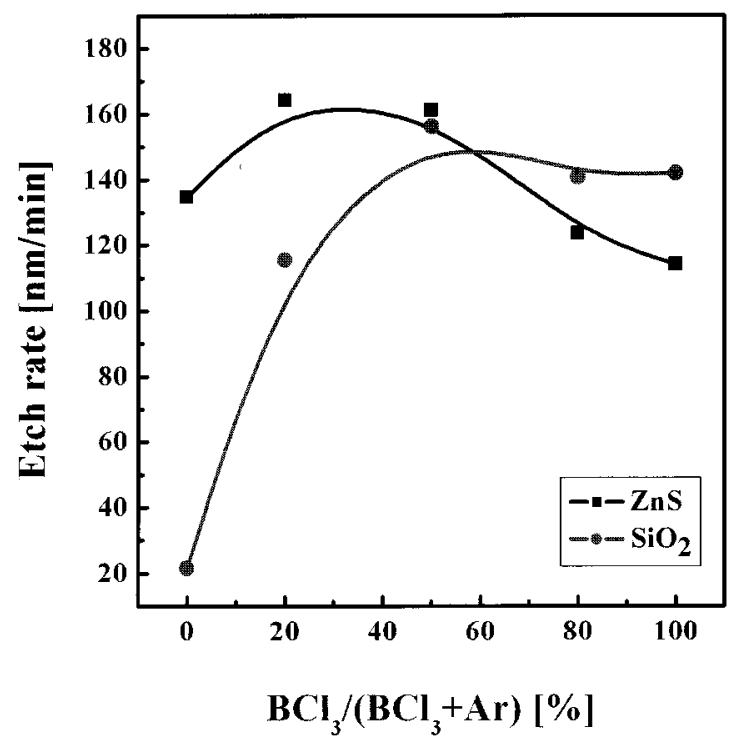

Fig. 1. Etch rate of $\mathrm{ZnS}: \mathrm{Mn}$ and $\mathrm{SiO}_{2}$ as a function of $\mathrm{BCl}_{3} /\left(\mathrm{BCl}_{3}+\mathrm{Ar}\right)$ gas mixing ratio.

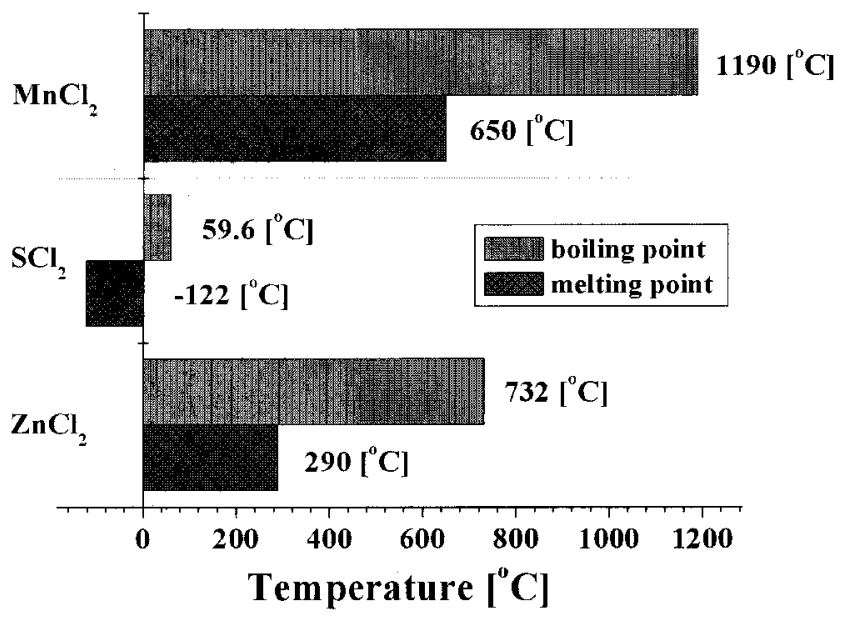

Fig. 2. Melting point and boiling point of $\mathrm{ZnS}: \mathrm{Mn}$ etching byproducts.

such as $\mathrm{MnCl}_{2}$ (melting point(MP) $=650^{\circ} \mathrm{C}$ ) and $\mathrm{ZnCl}_{2}$ $\left(\mathrm{MP}=290^{\circ} \mathrm{C}\right.$ ), as shown Fig. 2. Among them, $\mathrm{MnCl}_{2}$ is extremely low volatile compound. This fact supposes a negligible role of thermal desorption for $\mathrm{Mn}-\mathrm{Cl}$ bonds and allows one to assume preliminary the $\mathrm{ZnS}: \mathrm{MN}$ etch mechanism as ion assisted process where the role of ion bombardment includes such effects as: 1) sputtering of main material; and 2) sputtering (ion stimulated desorption) of reaction products to provide the access of $\mathrm{Cl}$ atoms to the etched surface.

Figure 3 shows the effect of RF power on the etch rates of $\mathrm{ZnS}: \mathrm{Mn}$ and $\mathrm{SiO}_{2}$ at a $\mathrm{BCl}_{3} /\left(\mathrm{BCl}_{3}+\mathrm{Ar}\right)$ of $20 \%$. 


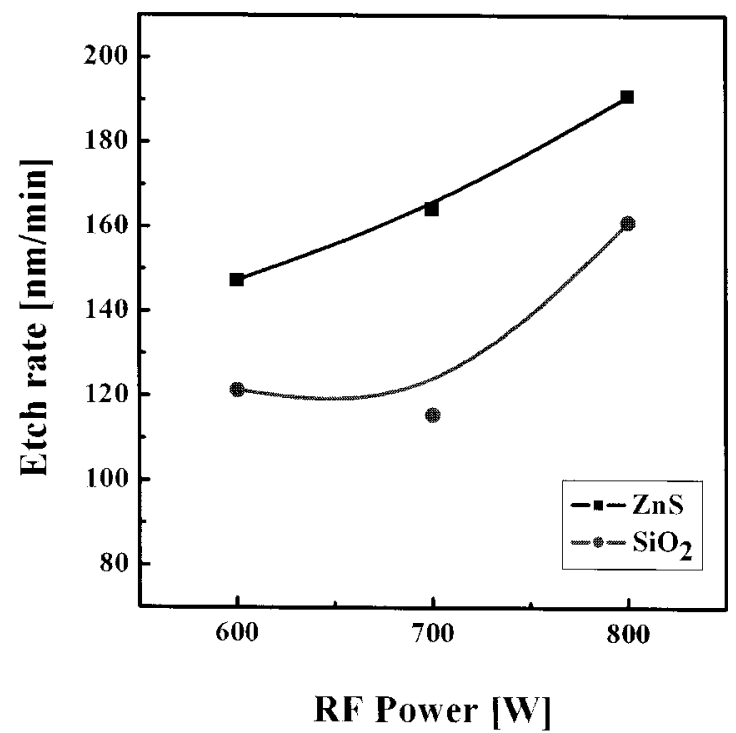

Fig. 3. Etch rate of $\mathrm{ZnS}: \mathrm{Mn}$ and $\mathrm{SiO}_{2}$ as a function of RF power.

Other process condition was equal to Fig. 1 . As the RF power increases from $600 \mathrm{~W}$ to $800 \mathrm{~W}$, the etch rates of $\mathrm{ZnS}: \mathrm{Mn}$ films increase from $147.3 \mathrm{~nm} / \mathrm{min}$ to 191.0 $\mathrm{nm} / \mathrm{min}$. The etch rate of $\mathrm{SiO}_{2}$ shows an increasing tendency (from $121.3 \mathrm{~nm} / \mathrm{min}$ to $161.1 \mathrm{~nm} / \mathrm{min}$ ) with increasing RF power. As the RF power increased, the plasma becomes more dissociated and increases both the fluxes and densities for ions and radicals. The increased plasma density leads to increasing etch rate. This result indicates that the acceleration of chemical as well as physical etch mechanisms take place simultaneously[7-10].

Figure 4 shows the etch rates of $\mathrm{ZnS}: \mathrm{Mn}$ and $\mathrm{SiO}_{2}$ as a function of $\mathrm{DC}$ bias voltage while other parameters were kept at constant; the $\mathrm{BCl}_{3} / \mathrm{Ar}$ gas mixture was $20 \%$, RF power was $700 \mathrm{~W}$, and working pressure was $1 \mathrm{~Pa}$, respectively. As DC bias voltage increased from -100 to $-250 \mathrm{~V}$, the etch rates of the $\mathrm{ZnS}: \mathrm{Mn}$ and $\mathrm{SiO}_{2}$ showed increasing tendency. The etch rates of ZnS:Mn increased from $69.5 \mathrm{~nm} / \mathrm{min}$ to $220.9 \mathrm{~nm} / \mathrm{min}$. The etch rate of $\mathrm{SiO}_{2}$ also increased from $65.6 \mathrm{~nm} / \mathrm{min}$ to $190.0 \mathrm{~nm} / \mathrm{min}$. The increase etch rate behavior of $\mathrm{ZnS}: \mathrm{Mn}$ can be explained by the fact that the ion bombardment energy increases with increasing DC bias voltage and results in the increasing sputtering yields both for main material and reaction products[11-13].

The etch rate as a function of working pressure is shown in Fig. 5. Other process condition was equal to Fig. 1. As the working pressure increase $0.5 \mathrm{~Pa}$ to $1 \mathrm{~Pa}$, the etch rate of $\mathrm{ZnS}: \mathrm{Mn}$ increased from $130.0 \mathrm{~nm} / \mathrm{min}$ to $164.2 \mathrm{~nm}$. As the working pressure increased further 1.5 $\mathrm{Pa}$ to $2 \mathrm{~Pa}$, the etch rate of $\mathrm{ZnS}: \mathrm{Mn}$ decreased from 155.4 $\mathrm{nm} / \mathrm{min}$ to $104.5 \mathrm{~nm} / \mathrm{min}$. The decreased etch rate of $\mathrm{ZnS}: \mathrm{Mn}$ at the $0.5 \mathrm{~Pa}$ can be explained by the disappearance

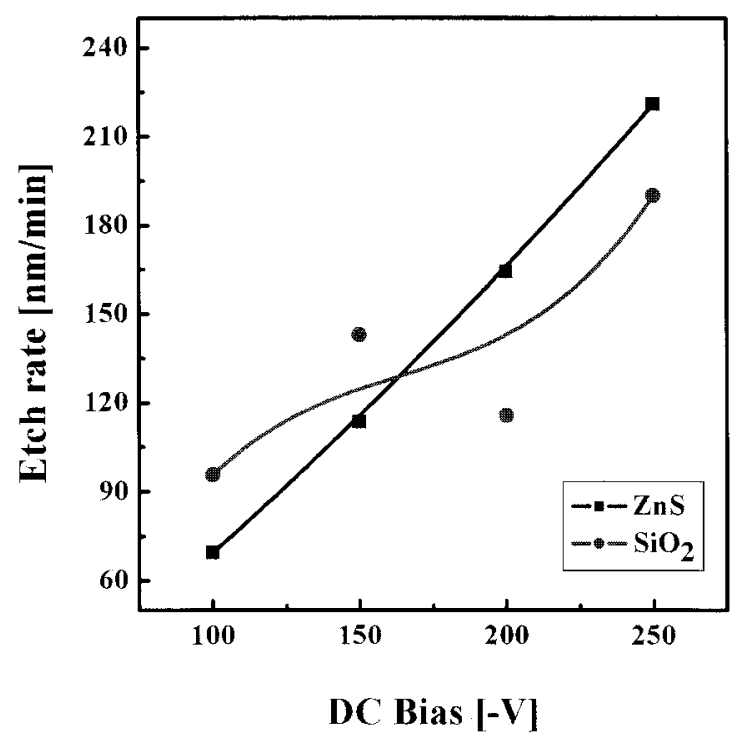

Fig. 4. Etch rate of $\mathrm{ZnS}: \mathrm{Mn}$ and $\mathrm{SiO}_{2}$ as a function of $\mathrm{DC}$ bias.

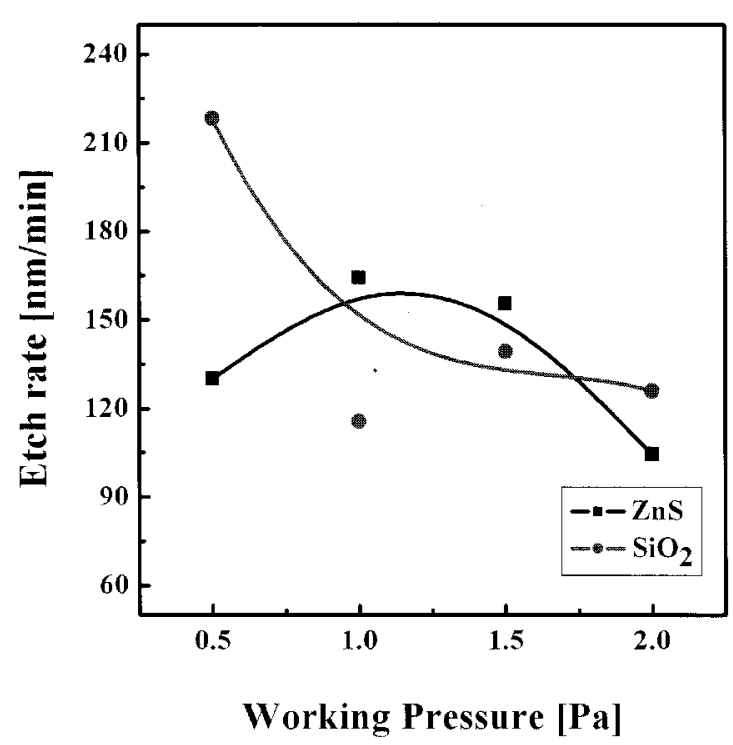

Fig. 5. Etch rate of $\mathrm{ZnS}: \mathrm{Mn}$ and $\mathrm{SiO}_{2}$ as a function of working pressure.

of chemical channel. However, the etch rate of $\mathrm{SiO}_{2}$ showed a decreasing tendency from $218.3 \mathrm{~nm} / \mathrm{min}$ to $126.0 \mathrm{~nm} / \mathrm{min}$ with increasing working pressure from 0.5 $\mathrm{Pa}$ to $2 \mathrm{~Pa}$. Since the mean free paths of species are inversely proportional to pressure, the reduction in potential translates into a lower energy ion flux to the substrate surfaces. That is, high pressures yield lower ion bombardment energies. These phenomena reveals that the chemical etch and the physical etch take place simultaneously. 


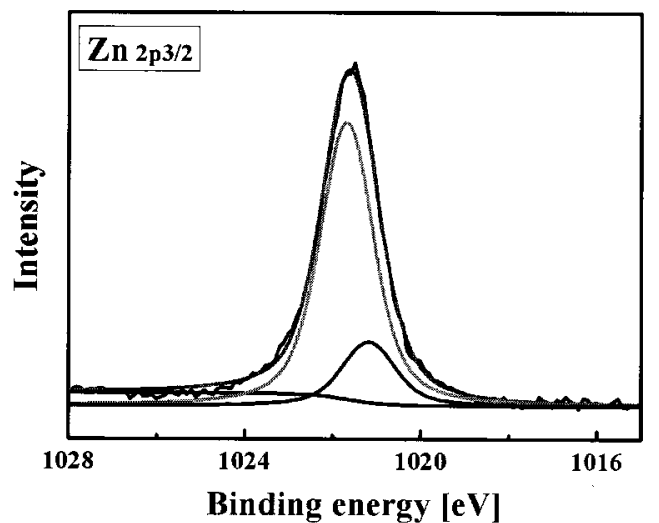

Fig. 6(a). Zn 2p XPS narrow scan spectra of ZnS:Mn surface etched with $\mathrm{BCl}_{3} / \mathrm{Ar}$ plasma.

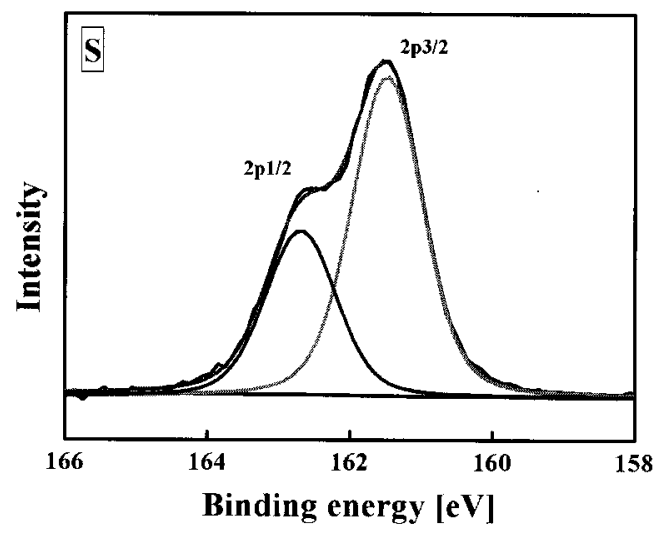

Fig. 6(b). S 2p XPS narrow scan spectra of ZnS:Mn surface etched with $\mathrm{BCl}_{3} / \mathrm{Ar}$ plasma.

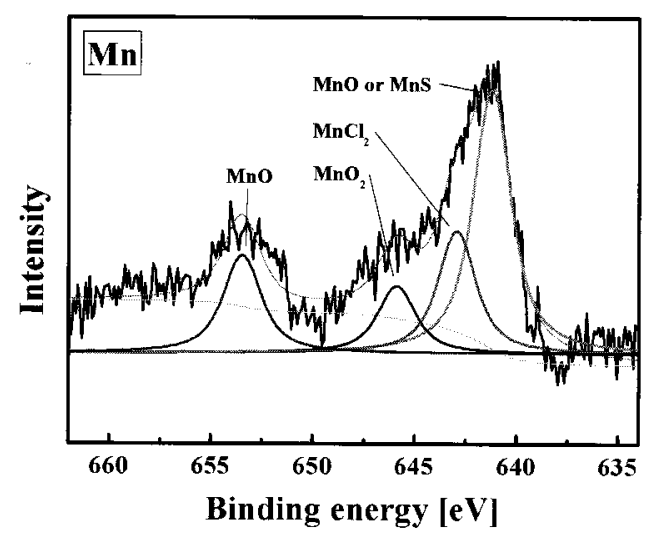

Fig. 6(c). Mn 2p XPS narrow scan spectra of ZnS:Mn surface etched with $\mathrm{BCl}_{3} / \mathrm{Ar}$ plasma.

In order to study how $\mathrm{Zn}, \mathrm{S}$, and $\mathrm{Mn}$ combine with $\mathrm{Cl}$ radical, the XPS analysis was performed. The variation of $\mathrm{Zn}, \mathrm{S}$, and $\mathrm{Mn}$ peaks of etched $\mathrm{ZnS}: \mathrm{Mn}$ surfaces is shown in Fig. 6. Figure 6(a) shows $\mathrm{Zn} 2 \mathrm{p}_{3 / 2}$ narrow scan spectra of the etched surface of $\mathrm{ZnS}: \mathrm{Mn}$ thin films. The peaks at the binding energies of 1021.71 and $1021.21 \mathrm{eV}$ in Fig. 6(a) can be assigned to $\mathrm{ZnS}$ and $\mathrm{Zn}$ of the $\mathrm{Zn}-\mathrm{S}$ bond, respectively. $\mathrm{ZnCl}_{2}$ has slightly lower vapor pressures, as shown in Fig. 2. This compound could easily vaporize from etched surface through the ionstimulated desorption of the reaction products. Figure 6 (b) represents S $2 p$ narrow scan spectra. The peaks at the binding energies of 161.45 and $162.65 \mathrm{eV}$ in Fig. 6(b) can be assigned to $S 2 p_{3 / 2}$ and $S 2 p_{1 / 2}$ of the $\mathrm{Zn}-\mathrm{S}$ bond, respectively. The shapes of $S 2 p$ photoelectron peaks of the samples etched with $\mathrm{Cl}_{2}$ plasma were exactly the same as that of as-deposited ZnS film. This result can be supported by the high vapor pressures of the possible sulfur-compounds such as $\mathrm{S}_{2} \mathrm{Cl}_{2}(1 \mathrm{mmHg}$ at $\left.-7.4^{\circ} \mathrm{C}\right)[14]$. As shown in Fig. 6(a) and (b), $\mathrm{ZnClx}$ and $\mathrm{SCl}_{\mathrm{x}}$ spectra were not detected. This can be explained $\mathrm{ZnCl}_{\mathrm{x}}$ and $\mathrm{SCl}_{\mathrm{x}}$ compound is dramatically removed because $\mathrm{ZnCl}_{\mathrm{x}}$ and $\mathrm{SCl}_{\mathrm{x}}$ compound was volatile. Figure 6(c) shows that the Mn 2p narrow scan spectra can be resolved into the $\mathrm{MnO}(653.45 \mathrm{eV}), \mathrm{MnO}_{2}(645.85 \mathrm{eV})$, $\mathrm{MnCl}_{2}(642.96 \mathrm{eV})$ and $\mathrm{MnS}(641.26 \mathrm{eV})$ compounds. The accumulation of $\mathrm{Mn}$ was detected from XPS analysis. This result could be understood by the fact that $\mathrm{MnCl}_{2}$ of low vapor pressure $\left(10 \mathrm{mmHg}\right.$ at $\left.778^{\circ} \mathrm{C}\right)$ was supposed to be formed in the $\mathrm{BCl}_{3}$ plasma, and could not be easily removed from the surface during etch process [14].

\section{CONCLUSION}

In this paper, we investigated the etching characteristics of $\mathrm{ZnS}: \mathrm{Mn}$ thin films with using inductive coupled plasma of $\mathrm{BCl}_{3} / \mathrm{Ar}$. The maximum etch rate of $\mathrm{ZnS}: \mathrm{Mn}$ thin films was $164.2 \mathrm{~nm} / \mathrm{min}$ at a $\mathrm{BCl}_{3}(20) / \operatorname{Ar}(80)$ gas mixing ratio. The etch rate of $\mathrm{ZnS}: \mathrm{Mn}$ decreased as $\mathrm{BCl}_{3}$ addition increased over $20 \%$. The etch rates for $\mathrm{ZnS}: \mathrm{Mn}$ increased with increasing RF source power and DC bias voltage and decreasing working pressure. XPS analysis revealed that volatilization of both $\mathrm{Zn}$ and $\mathrm{S}$ occurs through the formation of metal chlorides. It was also detected that $\mathrm{Mn}$ was accumulated on the surface of $\mathrm{ZnS}: \mathrm{Mn}$ after etching in $\mathrm{BCl}_{3} / \mathrm{Ar}$ plasma. The etch data and XPS analysis confirmed the ion assisted chemical reaction in etching $\mathrm{ZnS}: \mathrm{Mn}$ by the concurrence of chemical and physical pathways.

\section{REREFENCES}

[1] G. J. Orloff, J. L. Elkind, and D. Koch, "Hydrogen based reactive ion etching of zinc sulfide", J. Vac. Sci. Technol. A, Vol. 10, No. 4, p. 1371, 1992.

[2] J. W. Lee, B. Pathangey, M. R. Davidson, P. H. Holloway, E. S. Lambers, A. Davydov, T. J. Anderson, and S. J. Pearton, "Comparison of 
plasma chemistries for dry etching of thin film electroluminescent display materials", J. Vac. Sci. Technol. A, Vol. 16, No. 3, p. 1944, 1998.

[3] S. H. Su, M. Yokoyama, and Y. K. Su, "Reactive ion etching of $\mathrm{ZnS}$ films for thin-film electroluminescent devices", Materials Chemistry and Physics, Vol. 50, No. 3, p. 205, 1997.

[4] G. J. Orloff, "Optical emission spectroscopy of zinc sulfide etch", J. Vac. Sci. Technol. A, Vol. 10, No. 5, p. 3065, 1992.

[5] S. J. Pearton and R. Ren, "Plasma etching of ZnS, $\mathrm{ZnSe}, \mathrm{CdS}$, and $\mathrm{CdTe}$ in electron cyclotron resonance $\mathrm{CH}_{4} / \mathrm{H}_{2} / \mathrm{Ar}$ and $\mathrm{H}_{2} / \mathrm{Ar}$ discharges", J. Vac. Sci. Technol. B, Vol. 11, No. 1, p. 15, 1993.

[6] G. H. Kim, K. T. Kim, D. P. Kim, C. I. Kim, C. S. Park, and K. H. Kwon, "Study on the etch characteristics of BST thin films by using inductively coupled plasma", J. Kor. Phys. Soc., Vol. 45, p. S724, 2004.

[7] R. J. Shul, L. Zhang, A. G. Baca, C. G. Willison, J. Han, S. J. Pearton, F. Ren, J. C. Zolper, and L. F. Lester, "High density plasma-induced etch damage in GaN", Mater. Res. Soc. Symp. Proc., Vol. 573, p. 271, 1999.

[8] K. P. Lee, K. B. Jung, A. Srivastava, D. Kumar, R. K. Singh, and S. J. Pearton, "Dry etching of $\mathrm{BaSrTiO}_{3}$ and $\mathrm{LaNiO}_{3}$ thin films in inductively coupled plasmas", J. Electrochem. Soc., Vol. 146, No. 10, p. 3778, 1999.

[9] J. Ding, J. S. Jenq, G. H. Kim, H. L. Maynard, J. S. Hamers, N. Hershkowiz, and J. W. Taylor, "Etching rate characterization of $\mathrm{SiO}_{2}$ and $\mathrm{Si}$ using ion energy flux and atomic fluorine density in a $\mathrm{CF}_{4} / \mathrm{O}_{2} / \mathrm{Ar}$ electron cyclotron resonance plasma", $\mathrm{J}$. Vac. Sci. Technol. A, Vol. 11, No. 4, p. 1283, 1993.

[10] F. A. Khan and I. Adesida, "High rate etching of $\mathrm{SiC}$ using inductively-coupled-plasma reactive ion etching in $\mathrm{SF}_{6}$-based gas mixtures", Appl. Phys. Lett., Vol. 75, No. 15, p. 2268, 1999.

[11] C. W. Chung, "Reactive ion etching of $\mathrm{Pb}\left(\mathrm{Zr}_{\mathrm{x}} \mathrm{Ti}_{1}\right.$ x) $\mathrm{O}_{3}$ thin films in an inductively coupled plasma", J. Vac. Sci. Technol. A, Vol. 16, No. 4, p. 1894, 1998.

[12] H. J. Woo, K. S. Chung, T. Lho, and R. M. Williams, "A newly calibrated laser-induced fluorescence (LIF) system for Ar ions with a single tunable diode laser", J. Kor. Phys. Soc., Vol. 48, No. 2, p. 260, 2006.

[13] K. N. Kim and G. Y. Yeom, "Characteristics of a large-area plasma source using internal multiple Utype antenna”, J. Kor. Phys. Soc., Vol. 48, No. 2, p. 256, 2006.

[14] D. P. Kim, C. I. Kim, and K. H. Kwon, "Etching properties of $\mathrm{ZnS}$ thin films in $\mathrm{Cl}_{2} / \mathrm{CF}_{4} / \mathrm{Ar}$ plasma", Thin Solid Films, Vol. 459, No. 1-2, p. 131, 2004. 